\title{
Numerical design of the Seed-Blanket Unit for the thorium nuclear fuel cycle
}

\author{
Mikołaj Oettingen ${ }^{1}$ and Katarzyna Skolik ${ }^{1}$ \\ ${ }^{1}$ AGH University of Science and Technology, al. Mickiewicza 30, 30-059 Krakow, Poland
}

\begin{abstract}
In the paper we present the Monte Carlo modelling by the means of the Monte Carlo Continuous Energy Burn-up Code of the 17x17 Pressurized Water Reactor fuel assembly designed according to the Radkowsky Thorium Fuel concept. The design incorporates the $\mathrm{UO}_{2}$ seed fuel located in the centre and $(\mathrm{Th}, \mathrm{U}) \mathrm{O}_{2}$ blanket fuel located in the peripheries of fuel assembly. The high power seed region supplies neutrons for the low power blanket region and thus induces breeding of fissile ${ }^{233} \mathrm{U}$ from fertile ${ }^{232} \mathrm{Th}$. The both regions are physically separated and thus this approach is also known as either the heterogonous approach or the Seed-Blanket Unit. In the numerical analysis we consider the time evolutions of infinite neutron multiplication factor, axial/radial power density profile, ${ }^{233} \mathrm{U},{ }^{235} \mathrm{Uand}$ ${ }^{232} \mathrm{Th}$.
\end{abstract}

\section{Introduction}

The study focuses on the numerical modelling of the advanced nuclear system containing thorium fuel. Thorium occurs in nature in a single form of ${ }^{232} \mathrm{Th}$ and is about three times more abundant than uranium. It is a fertile isotope which captures a neutron and transmutes to the fissile ${ }^{233} \mathrm{U}$. For this reason thorium fuel has to be combined with another material able to provide sufficient neutron flux, such as ${ }^{233} \mathrm{U},{ }^{235} \mathrm{U}$ or ${ }^{239} \mathrm{Pu}$. After irradiation of thorium, the share of power generated by produced ${ }^{233} \mathrm{U}$ is increasing. The process in which ${ }^{232} \mathrm{Th}$ is transformed into ${ }^{233} \mathrm{U}$ is presented below.

$$
n+{ }_{90}^{232} \mathrm{Th} \rightarrow{ }_{90}^{233} \mathrm{Th} \stackrel{\beta^{-}(22 \mathrm{~min})}{\longrightarrow} 233{ }_{91} \mathrm{~Pa} \stackrel{\beta^{-}(27 d)}{\longrightarrow}{ }_{92}^{33} U
$$

Introduction of thorium to the general use in nuclear power plants (NPP) would increase fuel diversification and safety of supply. It would also vastly prolong the sufficiency of estimated conventional nuclear fuel, which is about 100 years for today [1]. The advantages of thorium fuel cycle together with its drawbacks comparing to traditional uranium cycle are presented below [2].

\section{Advantages:}

- Good chemical and physical properties: higher melting point, higher thermal conductivity and chemical stability, lower coefficient of thermal expansion, less gas fission products released $[3,4]$,

-Less minor actinides and plutonium in spent fuel,
-Proliferation resistance: irradiated fuel contaminated with easily detectable ${ }^{232} \mathrm{U}$,

-Possibility of breeding fuel in thermal reactors, -Thorium is more abundant, safer and more effective in mining.

\section{Disadvantages}

-Neutron source required to produce fissile ${ }^{233} \mathrm{U}$ from ${ }^{232} \mathrm{Th}$,

-Difficult and costly fuel fabrication for potential close fuel cycle because of high $\gamma$ radiation from ${ }^{232} \mathrm{U}$,

- Relatively long time of ${ }^{232} \mathrm{Th}$ breeding to ${ }^{233} \mathrm{U}$ due to ${ }^{233} \mathrm{~Pa}$ half-life of 27 days,

-Likelihood of using ${ }^{233} \mathrm{U}$ for nuclear weapon,

- Need of many costly researches and licensing processes before starting industrial use.

\section{Research programs}

There was a significant interest in thorium fuel cycle in the first years of nuclear energy, 1950-1970. The experimental reactors were built in the USA, Germany and UK. Most of them were High-Temperature Reactors (HTR), either with prismatic or pebble-bed fuel configuration, namely Peach Bottom and Fort St Vrain in the USA, Dragon in the UK, Arbeitsgemeinschaft Versuchsreaktor (AVR) and Thorium High-Temperature Reactor (THTR) in Germany [5].

In 1980s the support for nuclear power declined dramatically after the events in the Three Mile Island and Chernobyl. Prices of uranium decreased and the enthusiasm for alternative fuel cycles disappeared. Only in recent years some countries have 
become interested again in researches on thorium, some of them are Canada, China, India, Norway and the USA [6].

The most ambitious program was launched in India which has very limited resources of uranium and probably the biggest deposits of thorium in the world. The program is divided in three steps. In the first stage Pressurized Heavy Water Reactors (PHWR) fuelled by natural uranium will be used, where the plutonium is routinely produced. It can be than burned in the second stage with use of fast neutron reactors. Uranium and thorium present on the blanket around the core will produce further plutonium together with ${ }^{233} \mathrm{U}$. In the last step the Advanced Heavy Water Reactors (AHWR) will burn $\mathrm{Th} / \mathrm{Pu}$ fuel and continuously breed ${ }^{233} \mathrm{U}$. An alternative for the third stage is a Molten Salt Breeder Reactor (MSR). Until now about 1 tone of thorium oxide fuel has been irradiated experimentally in the PHWR reactors. The prototype $500 \mathrm{MWe}$ fast breeder reactor is expected to be operating in 2016 at Kalpakkam and six more fast reactors have been announced for construction. Design of the first $300 \mathrm{MWe}$ AHWR is now completed and the construction will start in 2016/17 with operation about 2022.

\section{Seed-Blanket Unit}

For the usage of thorium in Pressurized Water Reactors (PWR) two main fuel designs are considered: homogeneous and heterogeneous. The first approach assumes using the mixture of thorium and uranium oxides within each fuel rod while the second one considers placing thorium and uranium in separated regions, called the blanket and the seed, respectively. The heterogeneous design is far better for the effective conversion of ${ }^{232} \mathrm{Th}$ into fissile ${ }^{233} \mathrm{U}$. This approach once again considers two different concepts: Seed-Blanket Unit (SBU) and the whole assembly seed and blanket (WASB) [7]. SBU is also known as Radkowsky Thorium Fuel (RTF), named after Alvin Radkowsky, American nuclear physicist and a big proponent of using thorium as a fuel in NPPs.

The SBU represents the fuel assembly (FA) that consists of uranium "seed" in the center and thorium "blanket" around it as it is presented in Fig 1. Therefore all the assemblies in the reactor core are composed identically. Such design considers open fuel cycle, which means that ${ }^{233} \mathrm{U}$ is continuously produced and burned in the blanket and the fuel is not recycled afterwards. The blanket region is initially composed of $\mathrm{ThO}_{2}$ and $\mathrm{UO}_{2}$, where uranium oxide represents about $10 \%$ by volume. The seed can be either in metallic (U/Zr) or oxide $\left(\mathrm{UO}_{2}\right)$ form. However the second one was already widely used in nuclear power industry and has slightly better economic and neutronic performance than the first one. As such is was accepted as a part of seed in thorium-fuelled PWRs and also chosen for present study. Both in the blanket and in the seed enrichment of uranium is about $20 \%$.

\section{Simulations}

The numerical simulations of the SBU were performed by the means of the Monte Carlo Continuous Energy Burnup Code (MCB) developed at the Department of Nuclear Energy, Faculty of Energy and Fuels of the AGH University of Science and Technology, Krakow, Poland [8]. The MCB code couples well-known, general-purpose Monte Carlo N-Particle transport code (MCNP) with the state of the art Transmutation Trajectory Analysis code (TTA). The MCNP subroutines are used for the Monte Carlo neutron transport simulation while TTA subroutines for the calculations of isotopic changes due to nuclear transmutation and radioactive decay.

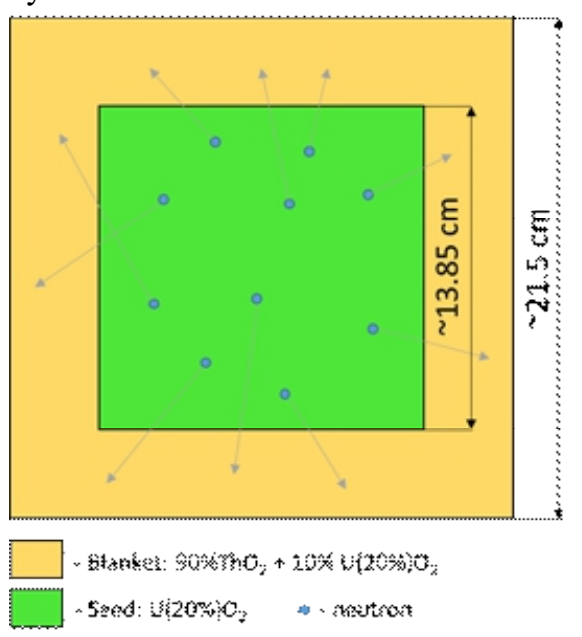

Figure 1. Fuel assembly in SBU design.

The code is implemented on the supercomputer Prometheus of the Academic Computer Center CYFRONET AGH, which allows fast and efficient Monte Carlo simulations. The PROMETHEUS is equipped in 55728 Intel CPUs, which gives the theoretical peak performance of 2399 TFlops. The cluster is ranked 39th in the TOP500 list of world's fastest supercomputers (November 2015) and is the fastest polish supercomputer dedicated for the scientific calculations.

The calculations were executed using two Hewllet Packard XL730f Gen9 nodes with 24 CPUs per node, of the type Intel Xeon E5-2680v3 with base frequency $2.5 \mathrm{GH}$. The system eigenvalue (neutron multiplication factor) was calculated using the kcode mode of MCNP. The well-validated JEFF3.1 nuclear data libraries containing the vast set of cross section data were used for simulations of neutron transport while standard MCB libraries containing radioactive properties of isotopes were used for burnup simulations. The total number of simulated neutron histories equals 7 million including 2 millions of inactive histories for fissile system convergence. The total execution time for one run equals about $5 \mathrm{~h}$ and gives the numerical precision below 30 pcm for neutron multiplication factor, which is sufficient for reliable simulations. The simulation was performed for the reactor cycle of one year with twelve burnup steps of one month. 


\section{Geometry}

Fig. 2 presents the horizontal cross section of the applied numerical model representing $17 \times 17$ fuel assembly. The transformation of the engineering geometry to the numerical geometry was based on the FA design dedicated for the Evolutionary Power Reactor (EPR) designed by French company AREVA. The main parameters of the fuel assembly are presented in Table 1. It is worth mentioning that the active height of the assembly was enlarged from 3.66 to 4.20 meters, what is strictly related to the larger power output of EPR $\left(1.65 \mathrm{GW}_{\mathrm{el}}\right)$ comparing with PWR of III generation like e.g. 4-loop Westinghouse reactor $\left(1.1 \mathrm{GW}_{\mathrm{el}}\right)$. Hence, the system was normalized to the average thermal power of single EPR fuel assembly of $18.67 \mathrm{MW}_{\mathrm{th}}$.

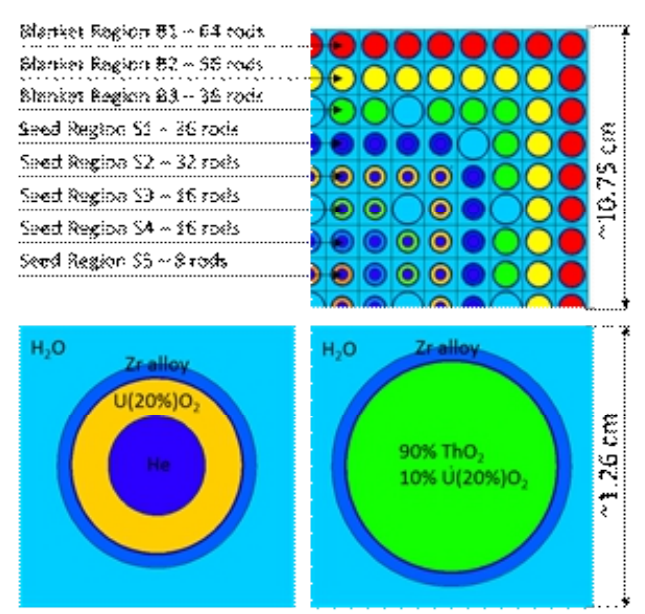

Figure 2. Numerical model of investigated fuel assembly.

According to the Radkowsky Thorium Fuel concept the seed region is surrounded by the thorium blanket region. The fuel rods were grouped into eight radial and seven axial fuel regions, which gives in total 56 independent fuel zones. The length of one axial segment equals $60 \mathrm{~cm}$. This type of division was applied for detailed reconstruction of isotopic changes in nuclear fuel across whole fuel assembly. The seed region comprises five radial regions with angular fuel rods containing enriched uranium fuel, while blanket region three radial regions with compact fuel rods containing fertile thorium fuel with some uranium. The multiple layers of neutron reflector containing water and structural materials were placed below and over active column. The reflective boundary conditions surround the FA.

\section{Results}

The numerical simulation with the MCB code provides a number of output files containing many sets of numerical data. In this study we mainly focus on the general parameters of the fuel assembly like infinite neutron multiplication factor, power distribution and evolution of fissile ${ }^{235} \mathrm{U},{ }^{233} \mathrm{U}$ and fertile ${ }^{232} \mathrm{Th}$.

Fig. 3 shows the evolution of the infinite neutron multiplication factor. The initial large drop in $\mathrm{K}_{\text {inf }}$ is caused by the formation of absorbing fission products especially ${ }^{135} \mathrm{Xe}$. Starting from about 30 days of irradiation $\mathrm{K}_{\text {inf }}$ drops in linear manner, which is strictly associated with the depletion of ${ }^{235} \mathrm{U}$ over reactor cycle. The investigated fuel assembly is strongly supercritical even at the end of cycle (EOC), which is caused by the high enrichment of the initial uranium fuel.

Table 1. Parameters of Seed-Blanket-Unit fuel assembly [9].

\begin{tabular}{|c|c|}
\hline \multicolumn{2}{|c|}{ Assembly } \\
\hline Rod Pitch & $1.26 \mathrm{~cm}$ \\
\hline Active lenght & $4.20 \mathrm{~m}$ \\
\hline Coolant & $\mathrm{H}_{2} \mathrm{O}$ \\
\hline $\mathrm{Nr}$ of rods & 264 \\
\hline Layout & $17 \times 17$ \\
\hline Clading type & Zircoalloy \\
\hline Clad thickness & $0.57 \mathrm{~mm}$ \\
\hline He gap thickness & $0.08 \mathrm{~mm}$ \\
\hline \multicolumn{2}{|c|}{ Blanket } \\
\hline Fuel Type & $90 \% \mathrm{wt} \% \mathrm{ThO}_{2}+10 \mathrm{wt} \% \mathrm{UO}_{2}$ \\
\hline Enrichemnt & $20 \%$ \\
\hline Density & $9.4 \mathrm{~g} / \mathrm{cm}^{3}, 94 \%$ of TD \\
\hline Mass & $\sim 418.4 \mathrm{~kg}$ \\
\hline Pellet radius & $4.65 \mathrm{~mm}$ \\
\hline Rod radius & $0.53 \mathrm{~cm}$ \\
\hline \multicolumn{2}{|r|}{ Seed } \\
\hline Fuel Type & $\mathrm{UO}_{2}$ \\
\hline Enrichemnt & $20 \%$ \\
\hline Density & $10.3 \mathrm{~g} / \mathrm{cm}^{3}, 94 \%$ of TD \\
\hline Mass & $\sim 146.5 \mathrm{~kg}$ \\
\hline Pellet outer radius & $3.85 \mathrm{~mm}$ \\
\hline Pellet inner radius & $2.20 \mathrm{~mm}$ \\
\hline Rod radius & $5.30 \mathrm{~mm}$ \\
\hline
\end{tabular}

Fig. 4 shows the net increase/decrease of the ${ }^{235} \mathrm{U}$, ${ }^{233} \mathrm{U}$ and ${ }^{232} \mathrm{Th}$ over twelve 30 days-long time steps. The net decrease in uranium ${ }^{235} \mathrm{U}$ falls from step to step because the ongoing consumption due to fission. Moreover its consumption is compensated by fission of newly bred ${ }^{233} \mathrm{U}$ and ${ }^{239} \mathrm{Pu}$. The net decrease of ${ }^{232} \mathrm{Th}$ due conversion to ${ }^{233} \mathrm{U}$ via ${ }^{233} \mathrm{~Pa}$ shows average constant value of 245 grams for all considered time steps. It means that ${ }^{232} \mathrm{Th}$ conversion just merely depends on changes of isotopic concentration in the fuel assembly and it can reach some upper limit, providing constant assembly power. The total conversion of ${ }^{232} \mathrm{Th}$ over reactor cycle equals about $3 \mathrm{~kg}$ while the depletion of ${ }^{235} \mathrm{U}$ about $9 \mathrm{~kg}$.

Fig. 5 depicts the power profile distribution at the middle of cycle (MOC), which is necessary for the estimation of the hot spots in the fuel assembly for further thermal-hydraulic calculations. The power is mainly released in the inner seed region containing high enriched uranium fuel. The highest power density was determined in the fourth seed radial region at the interface with the blanket thorium region. 


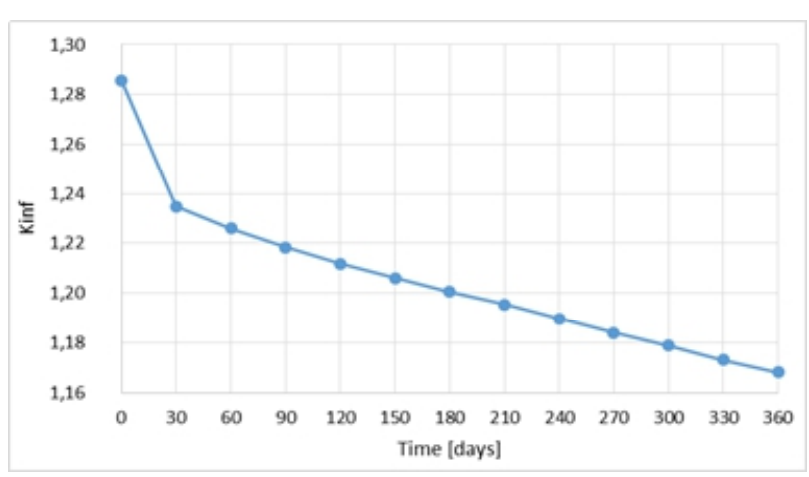

Figure 3. Evolution of infinite neutron multiplication factor.

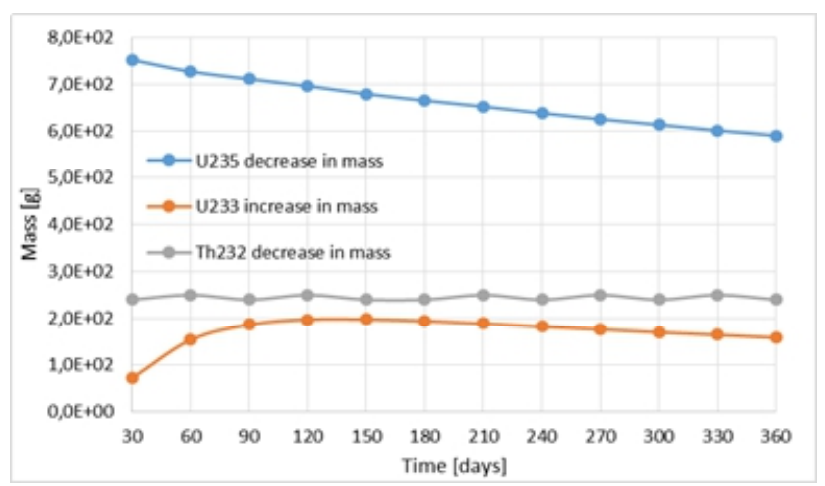

Figure 4. Evolution of ${ }^{233} \mathrm{U},{ }^{235} \mathrm{U}$ and ${ }^{232} \mathrm{Th}$.

Fig. 6 shows the detailed axial power evolution for the beginning of cycle (BOC), MOC and EOC for these regions. Moreover, the power profiles undergo flattening due to the enhanced fuel burnup in the central fuel zones.

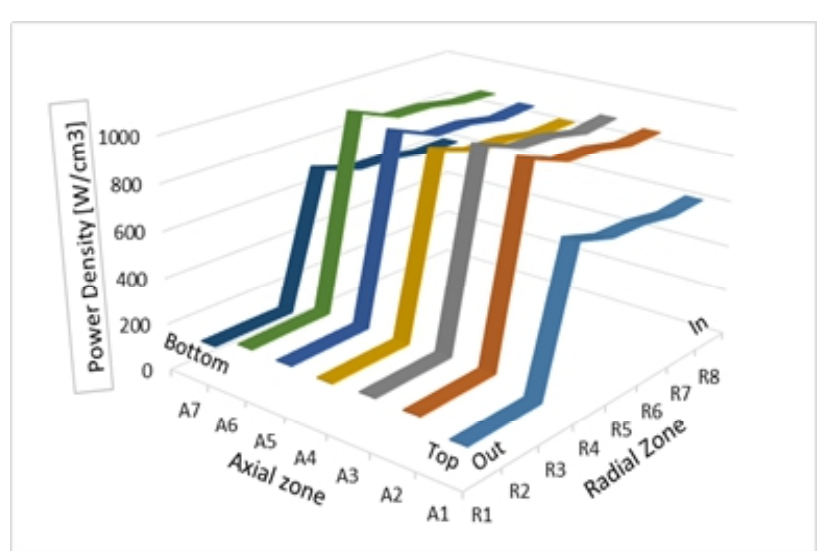

Figure 5. Power density distribution at MOC.

\section{Conclusions}

In the paper we have presented the Monte Carlo modelling of the EPR 17x17 fuel assembly designed for the thorium utilisation. The advanced numerical tools were used for the creation of the simulation setup for the high multiscale modelling with high performance computer Prometheus. The study shows that:

- The MCB code is the advanced numerical tool, which allows detailed modelling of the nuclear systems working on Th-U fuel,
- The obtained numerical results provide the reliable basis for subsequent research on $\mathrm{Th}-\mathrm{U}$ fuel foreseen for the PWR reactors,

- The study proves the breeding capability of the fissile ${ }^{233} \mathrm{U}$ from the fertile ${ }^{232} \mathrm{Th}$ in existing and future nuclear reactors cooled and moderated by light water - see Fig. 4 .

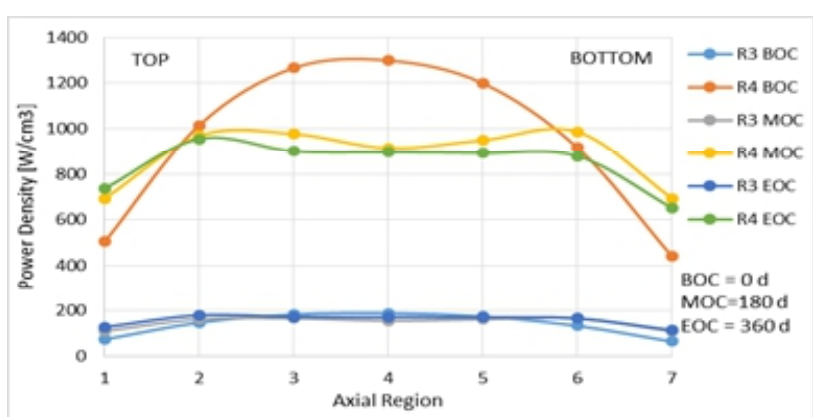

Figure 6. Axial power profile for hottest seed and blanket axial regions.

The future research on the Th-U fuel cycle modelling with MCB should focus on the estimation of safety parameters at the level of the whole reactor core. This, in turn demands development of the more advanced, high resolution, numerical models to determine the characteristics of the fissile system with the high numerical precision. In addition, the comparative analysis of actinide concentrations between numerical simulation and experimental assay would help to validate designed numerical setup.

\section{Acknowledgements}

The research was supported in part by PL Grid Infrastructure available at Academic Computer Centre CYFRONET AGH. In addition, partial financial support of this study through the funds of the Polish Ministry of Science and Higher Education is kindly acknowledged.

\section{References}

1. D.E. Sefrontein, E.J. Mulder, Thorium-based fuel cycles: Reassessment offuel economics and proliferation risk. Nucl Eng Des 271, 106-113 (2014)

2. K.I. Björk et al., Commercial thorium fuel manufacture and irradiation: Testing (Th,Pu) $\mathrm{O}_{2}$ and $(T h, U) \mathrm{O}_{2}$ in the "Seven-Thirty" program, Ann Nucl Energy 75, 79-86 (2015)

3. L.P. Tucker, A. Alajo, S. Usman, Thorium-based mixed oxide fuel in a pressurized water reactor: A beginning of life feasibility analysis with MCNP, Ann Nucl Energy 76, 323-334 (2015)

4. S.S. Drera, K.I. Björk, J.F. Kelly, Thorium fuel production and results from beginning of life irradiation, Prog Nucl Energ 72, 5-10 (2014)

5. D. Greneche, M. Chhor, Development of the thorium fuel cycle, Woodhead Publishing Limited (2012)

6. B. Graves, A. Wong, K. Mousavi, Ch. Canter, A. Kumar, Techno-economic assessment of thorium power in Canada, Ann Nucl Energy 85, 481-487 (2015) 
7. IAEA, Thorium fuel cycle - Potential benefits and challenges, Vienna, (2005)

8. G.Kępisty, J. Cetnar, P. Stanisz, Parametric studies of the PWR fuel assembly modeling with Monte-Carlo method, Ann Nucl Energy 94, 189-207 (2016)

9. S.F. Ashley et al., Fuel cycle modelling of open cycle thorium-fuelled nuclear energy systems, Ann Nucl Energy 69, 314-330 (2014) 